\title{
Tube cystostomy for management of obstructive urolithiasis in ruminants
}

\author{
P. Tamilmahan ${ }^{1}$, A. Mohsina ${ }^{1}$, K. Karthik ${ }^{2}$, M. Gopi ${ }^{3}$, M. B. Gugjoo ${ }^{1}$, Rashmi ${ }^{1}$ and M. M. S. Zama
}

1. Division of Veterinary Surgery, Indian Veterinary Research Institute, Izatnagar, Bareilly, 243 122, Uttar Pradesh, India;

2. Division of Bacteriology, Indian Veterinary Research Institute, Izatnagar, Bareilly, 243122 , Uttar Pradesh, India;

3. Division of animal nutrition, Indian Veterinary Research Institute, Izatnagar, Bareilly, 243 122, Uttar Pradesh, India

Corresponding author: P. Tamilmahan, email:dr.tamilmahan_vet@yahoo.com, Cell: +91-8430875118

Received: 17-02-2014, Revised: 15-03-2014, Accepted: 17-03-2014, Published online: 14-04-2014

doi: $10.14202 /$ vetworld.2014.234-239

How to cite this article: Tamilmahan P, Mohsina A, Karthik K, Gopi M, Gugjoo MB, Rashmi and Zama MMS (2014) Tube cystostomy for management of obstructive urolithiasis in ruminants, Veterinary World 7(4): 234-239.

\begin{abstract}
Aim: The aim of this study was to evaluate the simple tube cystostomy procedure for management of urethral obstruction cases in ruminants.

Materials and Methods: Tube cystostomy was used to treat a total of 58 ruminants, which included 35 buffalo calves and 23 goats. Diagnosis of the disease was made with the history of anuria, clinical signs, and physical examinations. Physical parameters like heart rate, respiratory rate, rectal temperature dehydration status of animals by skin tenting test, and intraoperative findings were compared.

Results: Young ruminants were most commonly affected and the mean age was 4-5 months in both species. Only male were considered for the study in which buffalo calves were not castrated but in goat's $73.91 \%$ animal were castrated and $34.7 \%$ not castrated. Rupture of bladder was more common in buffalo calves as compared to goats. The confirmed cases of obstructive urolithiasis were selected for tube cystostomy with Foley's catheter. Postoperatively all cases were administered with broad spectrum antibiotic, anti-inflammatory agent, and caliculolytic agents like ammonium chloride. Postoperative complications recorded only in 10 animals and remaining 48 animals had an uneventful recovery.
\end{abstract}

Conclusion: Tube cystostomy is a simple and effective procedure particularly in intact urinary bladder, which can be adopted at field level.

Keywords: ruminants, tube cystostomy, urolithiasis.

\section{Introduction}

Urolithiasis describes the concretion of urinary calculi or organic compound, which may lodge anywhere in the urinary system but most frequently at the distal end of sigmoid flexure in ruminants, and causes subsequent urine flow obstruction $[1,2]$. Occurrence of urolithiasis is significantly more common in male ruminants compared to females due to their anatomical conformation of the urethral tract [3]. The Female have short, wide, and straight urethra while the male has long, narrow and tortuous urethra which makes them more prone to urethral obstruction, particularly distal aspect of the sigmoid flexure in bovines and urethral process in sheep and goats. Early castration of male animals might be the one of the reason because it causes hypoplasia of urethra and leading to reduction in bore size of urethra. The decreased urethral orifice is a major predisposing factor for obstructive urolithiasis [3]. In addition, calculi formation usually results from a combination of nutritional, physiological, geographical, seasonal, age, sex and management factors [4].

Obstructive urolithiasis in ruminants has been corrected with medical treatment but the result is unrewarding one. Treatment of obstructive urolithiasis

Copyright: The authors. This article is an open access article licensed under the terms of the Creative Commons Attribution License (http://creativecommons.org/licenses/by/2.0) which permits unrestricted use, distribution and reproduction in any medium, provided the work is properly cited. is definitely surgical, once the obstruction is complete. Removal of calculi may be by direct or indirectly bypassing the obstruction [5]. Surgical tube cystotomy is the most commonly used treatment for long term management of obstructive urolithiasis in animals and may be the best option for breeding animals. It redirects the urine through a catheter placed from urinary bladder and exiting through the abdominal wall. The success rate of this technique has been reported to be $80 \%$ after 1 month of postoperative period [6]. The advantages of this technique are it is a simple procedure, highly field applicable, a relatively short duration of anaesthesia and attains a full urethral patency in short period of time.

The present study described the clinical signs and surgical management of obstructive urolithiasis.

\section{Materials and Methods}

Ethical approval: Ethical approval was not necessary. All the clinical cases under this research were treated and examined as per standard treatment and examination procedure.

Animals: The present study was conducted at the Division of Surgery and Radiology, Referral Veterinary Polyclinic, Indian Veterinary Research InstituteIzatnagar. Total 58 male animals, in which 35 buffalo calves and 23 goats were formed the material of the study, which were suffering from complete retention of 


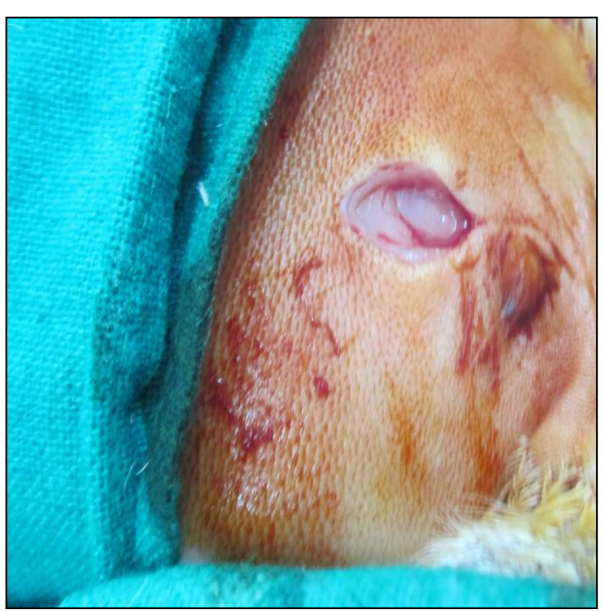

Figure-1: Skin incision at anterior to the rudimentary teat.

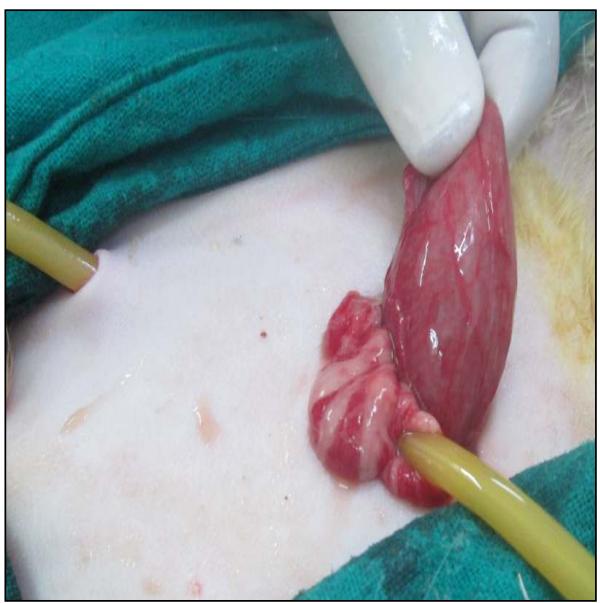

Figure-3: Indwelling Foleys catheter was inserted into subserous ruptured bladder

urine and presented for treatment at Referral Veterinary Polyclinic.

These animals were subjected to a thorough clinical examination to check the condition of animals. Physical examination was done to check the status of the urethra and urinary bladder and physiological parameters like heart rate $(\mathrm{H} / \mathrm{R}$, beats/minute), respiratory rate $\left(\mathrm{R} / \mathrm{R}\right.$, beats/ minute), rectal temperature $\left({ }^{\circ} \mathrm{C}\right)$, colour of mucus membrane and dehydration status by skin tenting test for confirmation of the tentative diagnosis. Intra operatively the bladder was examined whether it is intact/ruptured, appearance of bladder (smooth, rough, inflamed and necrosed). Animals were stabilized preoperatively with fluid therapy and supportive therapy to those animals which have severe dehydration and uraemia as the case required. Stabilized animals were prepared for tube cystotomy and operated on same day.

Surgical procedure: All the animals were anaesthetised with local anaesthetic $2 \%$ lignocaine at lumboscaral epidural and line infiltration at surgical site. Animals were placed in right lateral recumbency. Left side of the abdomen near the rudimentary teat area was cleanly shaved and scrubbed with antiseptic solution. After scrubbing, an incision was made nearly

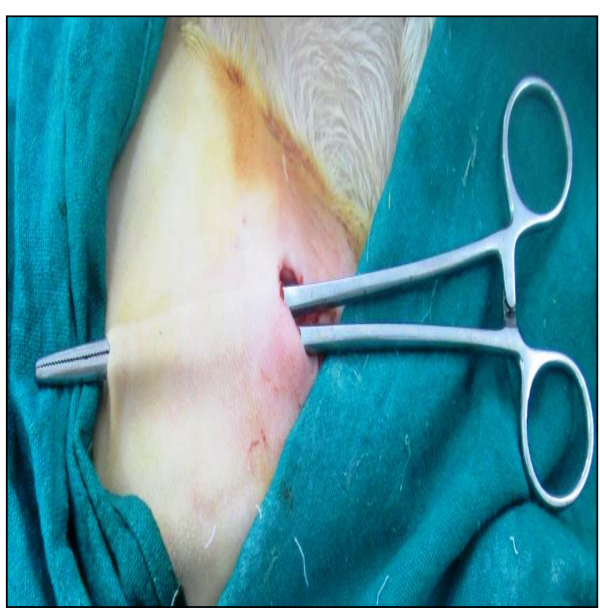

Figure-2: Foleys catheter passed through the subcutaneous tunnel

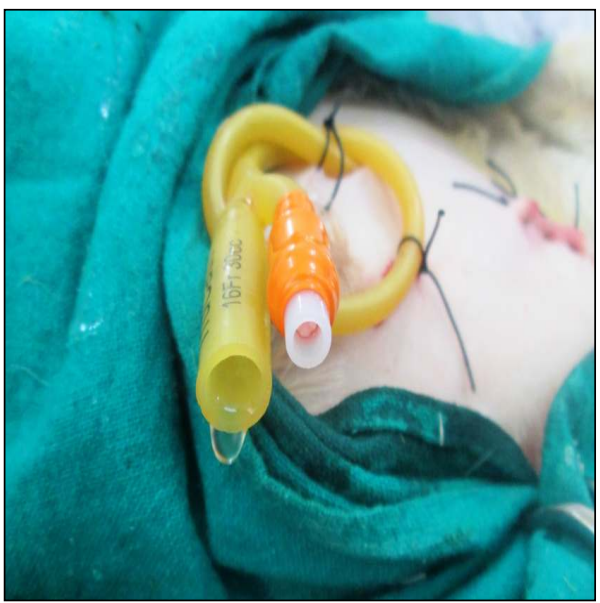

Figure-4: Catheter secured in abdominal skin with stay suture and free flow of urine through catheter.

anterior to the rudimentary teat; bladder was located after separating subcutaneous tissue and muscles by blunt incision (Figure-1). The status of bladder was checked whether intact or ruptured and appearance of the bladder also noted. If bladder intact, subcutaneous tunnel was made parallel to the prepuce by passing straight mosquito forceps through the subcutaneous tissue at the end skin was incised intended for catheter outlet (Figure-2 and 3). Folye's catheter was passed from outside to abdominal cavity where the catheter tip was held in stilette and directly stabbed the bladder and its bulb was inflated with sterile normal saline for fixation. Conversely if bladder ruptured cystorraphy followed by catheter placement was done after necessary debridement and irrigated with normal saline to remove concretions and cystic calculi. Muscles and subcutaneous tissue was sutured with No.1 catgut in continuous suture pattern. Skin was sutured with horizontal mattress with nylon No. 1. The Foley's catheter was sutured at multiple sites on the ventral abdomen (Figure-4).

Postoperatively owners were advised to give antibiotic Entrofloxacin@5mg/kg b.wt, I/M for 6 days, analgesic, meloxicam @ $5 \mathrm{mg} / \mathrm{kg}$ for 3 days and ammonium chloride @ $200 \mathrm{mg} / \mathrm{Kg}$ b.wt, b.i.d. daily, 
Table-1: Distribution of cases and different occurrence of urolithiasis in ruminants

\begin{tabular}{|c|c|c|c|c|c|c|c|c|}
\hline Species & $\begin{array}{l}\text { Occurrence } \\
\text { (\%) }\end{array}$ & $\begin{array}{l}\text { Age in } \\
\text { months }\end{array}$ & $\begin{array}{c}\text { Occurrence } \\
(\%)\end{array}$ & Intact bladder & $\begin{array}{l}\text { Ruptured } \\
\text { bladder }\end{array}$ & Castrated & Uncastrated & $\begin{array}{l}\text { Skin tent test } \\
4-10 \% \\
(>2-10 \text { sec })\end{array}$ \\
\hline \multirow[t]{2}{*}{ Buffalo calves } & $35(60.34 \%)$ & $4-5(22)$ & $62.86 \%$ & $26(74.28 \%)$ & $\begin{array}{l}9(25.71 \%) \\
4 \text { (serosal rupture) } \\
3 \text { (severely necrosed) } \\
2 \text { (moderately necrosed) }\end{array}$ & Nil & $35(100 \%)$ & $\begin{array}{l}4-6 \%(26 / 35) \\
6-8 \%(9 / 35)\end{array}$ \\
\hline & & $\begin{array}{l}6-8(9) \\
8-10(4)\end{array}$ & $\begin{array}{l}25.71 \% \\
11.42 \%\end{array}$ & & & & & \\
\hline \multirow[t]{2}{*}{ Goats } & $23(39.66 \%)$ & $2(4)$ & $17.31 \%$ & $17(73.91 \%)$ & $\begin{array}{l}6(26.08 \%) \\
4 \text { (serosal rupture) } \\
2 \text { (necrosed) }\end{array}$ & $6(26.08 \%)$ & $17(73.91 \%)$ & $\begin{array}{l}4-6 \%(17) \\
6-8 \%(6)\end{array}$ \\
\hline & & $\begin{array}{l}4-5(13) \\
6-8(6)\end{array}$ & $\begin{array}{l}56.51 \% \\
26.08 \%\end{array}$ & & & & & \\
\hline
\end{tabular}

per Os for a period of one month. Application of local antiseptic dressing with povidone iodine was advised for a week. The catheter was allowed to drain freely for four days (or until normal urination resumed) after which it was clamped on every alternate day with infusion set flow regulating clamp to determine the urethral patency. All the animals were presented again to our hospital for removal of catheter if normal urination is resumed through the urethra. Similarly calves which had retention of urine due to blockage in urethra or the catheter were also presented for further treatment.

\section{Results}

The occurrence of urolithiasis most commonly encountered in winter season. Most of the animals, buffalo calves were not castrated but in goats 17 $(73.91 \%)$ animal were castrated and $6(26.08 \%)$ were not castrated. The age of calves mostly affected from 3-10 months (average age 4.5 month) and maximum number of animals between 4-5 months (62.8\%) followed by animals of 6-8 months (25.7\%) and 8-10 months $(11.42 \%)$. In goats the same strategy was followed $56.5 \%$ animals were in 4-5 months (average 4 months) and remaining $26.08 \%$ were in 6-8 months group and $17.3 \%$ were 2 months old. In both species young animals were mostly affected (Table-1).

Clinical signs of most of the animals with intact bladder were complete anorexia or inappetance, stranguria or anuria, reluctant to walk and frequent attempt to urination. Deep palpation on both side of abdomen found that out of 35 calves 26 were intact urinary bladder, remaining 9 cases were suspected for ruptured bladder. In goat most of the animals had intact bladder $17 / 23$ with remaining the $6 / 23$ animals were suspected for ruptured bladder. In case of ruptured urinary bladder, bilateral ventral distension of abdomen might be noted and confirmed with abdominocentesis in which urine present in abdomen. Among calves with ruptured bladder, 2 animals were in recumbent position and had bradycardia with louder heart sound.

On physical examination 6 calves showed tachycardia ( 95 beats /min range 40-120/min) and 3 goats showed tachycardia (mean 98 beats/minute ranges $60-100 / \mathrm{min}$ ). Rectal temperature of all the calves are in range of $37.5^{\circ} \mathrm{C}$ and goats in the range of $38.4^{\circ} \mathrm{C}$, which was within the normal reference value of calves (38.5$39.5^{\circ} \mathrm{C}$ ) and goats $\left(38.5-40.5^{\circ} \mathrm{C}\right)$. Dehydration status of animals was measured by skin tenting test, which showed that ruptured bladder cases had shrunken eye balls (sinking eye balls in the socket), severely dull and depressed and rough hair coat. Mild to moderate dehydration was notice in those animals which had intact bladder. The level of dehydration in animals ranged from $4-10 \%(>2-10 \mathrm{sec})$ in which most of the buffalo calves within 4-6\% (26 animals out of 35) remaining had 6-8\%. While in goats (17 out of 23 ) had $4-6 \%$ and remains (6 out of 23 ) had $6-8 \%$ of degradation.

All the cases attained adequate analgesia at surgical site, there was no complication encountered. Catheterization of urinary bladder and positioning of tube was achieved without any difficulties. After tube placement, flow of urine through the tube was observed in all the cases.

Those animals presented within 2 days (16 buffalo calves, 9 goats) of urinary obstruction cases were having healthy urinary bladder, appeared smooth and pink in colour intra operatively. Those cases which presented after 3 days (10 calves/ 8 goats) showed tensed bladder filled with urine, which appeared rough slightly and colour varied from pinkish to blue. In ruptured bladder cases out of 9 calves, 4 had serosal rupture, 3 were severely necrosed, remaining 2 moderately necrosed. In goats out of 6 two were necrosed and 4 animals had serosal rupture. Ruptured bladder cases mostly presented after 4 days to our hospital and the colour of bladder was more dark bluish in colour.

Post operatively the signs of acute pain and distress reduced immediately after surgery and animals started to feed normally after $6 \mathrm{hr}$. Different postoperative complications recorded in both the species, which included urethral rupture in 5 calves, 2 tube blocks and three goats tube blocks were encountered. In buffalo calves (80\%) and goats (86.7\%) animal got uneventful recovery without any complications and resumed normal urination through the urethra on 12-18 days of postoperatively onwards. Tube was removed after resuming normal urination through the external urethral orifice, the owner was advised to give more water and less concentrate feed. 


\section{Discussion}

Obstructive urolithiasis causes economic loss to the farmer due to loss of animals and cost of treatment. Mortality rate in cases of obstructive urolithiasis is very high which is mainly due to rupture of urethra or urinary bladder [7]. In the present study, affected animals age were within the range of 4-5 months in both buffalo calves and goats, this finding was in consistent with the study of Sharma et al. [8] who documented that $60 \%$ animals urethral obstruction occurs mostly in young ruminants. Similar results were observed by other workers on urethral obstruction of buffalo calves $[9,10]$. The incidence of urolithiasis was more common in male buffalo calves and goats compared to female animals. This may be due to anatomical confirmative changes in the urethra [11]. Castrated male goats had higher urethral obstruction when compared to intact males. This variation in occurrence is because after castration the production of testosterone was reduced which may cause hypoplasia of urethral orifice [12]. The reduction of testosterone may also decrease the protective hydrophilic colloid in the urine which increased the incidence of urolithiasis [3]. However, this variation was only noticed in goats not in buffalo calves. In addition desquamated epithelial cells can act as nidus for urethral calculi precipitation. Desquamated epithelial cells may be due to deficiency of vitamin A and infections [13].

Seasonal variation may be one of the causative agents because both in winter and summer the occurrence of urolithiasis is more. This may be related to water balance of animals, during winter animals will not take much water and produce concentrated urine [1]. Conversely, during the summer, urine may be more concentrated due to increased water loss in the heat. In our study most of the obstructive urolithiasis cases were come across only in winter seasons.

The prevalence of urolithiasis may occur due to imbalance of mineral intake in feed. Lot animals while fattening/growing received more cereals and concentrated feeds. These feeds contain more level of phosphorus and magnesium and relatively less level of calcium and potassium predisposed to this condition [14].

On physical examination most of the animals showed tachycardia, which was above the normal reference value. This was recorded by many authors in their cases of obstructive urolithiasis [15]. Increased heart rate may be due to the accumulation toxic metabolites/waste product which were produced in uremic animals [16]. In another study prolonged illness, anorexia, progressive systemic disturbance may result in electrolyte disturbances like hyponatremia and hyperkalemia in ruminants suggested as a possible causes of increasing heart rate in obstructive urolithiasis cases [17].

Respiratory rate was higher than the normal reference value, which could be due to pain produced by urethral obstruction, electrolyte disturbance like hypocalcemia, hypomagnesemia and hypovolumic shock [18]. Previous worker also reported the same in calves by Jadon et al. [19]

Rectal temperature of all the animals were within the normal range, which was concurrent with the study of Parrah et al. [20] in experimentally created urethral obstruction in calves. This was most likely due to various stages of uraemia, hemodynamic changes and degree of illness [21]. The dehydration was usually much more marked if water and electrolyte losses have been occurring over a period of several days. This results in loss of skin elasticity, dryness of the skin and mucosa, and a reduction and retraction of the eyeball (enophthalmia) due to reduction in the volume of the postorbital fat deposits [1]. Dehydration was more in cases of ruptured urinary bladder which might be due to the loss of fluid from the interstitial and intracellular spaces into peritoneal cavity [22].

Diagnosis of urethral obstruction cases can be much easier; however selecting treatment modalities is much more difficult. Treatments include medical dissolution of calculi and surgical management. In general less severe cases can be corrected with medical management. Some report says that medical treatment is not effective for long term and only provided temporary relief [23]. In more severely obstructed cases surgery is the only option.

Surgical tube cystostomy is the most promising procedure for obstructive urolithiasis in small ruminants intended for use as breeding animals. The procedure is relatively simple, requiring a short duration of anaesthesia and resulting in restoration of full urethral patency in successful cases [24, 5]. The free flow of urine through the external urethral orifice could be due to many factors. Such as by giving antiinflammatory drugs relived the spasm and inflammation of urethra, caliculolytic agent like ammonium chloride and sodium chloride along with water reduced $\mathrm{pH}$ of urine and it promotes the dissolution of calculi, bypassing of urine through the Foley's catheter may reduce the calculi size and frequent occlusion of catheter with clamp could bring urethral patency by flushing urethra of all debris and calculus material [23]. A retrospective study of short and long term outcome of surgical tube cystostomy in ruminants reported reobstruction of catheter was minimal compare to previous studies and attributed with recommended dietary management at the time of discharge [23]. Complication of tube cystostomy might be due to blockade of tube with blood or tissue debris, urethral rupture, tube dislodgement, and infection [25]. Different surgical treatments are available for obstructive urolithiasis but each operation having their own advantages and disadvantages. Tube cystostomy surgery provides alternatives to those operations. Perineal Urethrotomy (PU) and urethrostomy has been used to relive the obstruction on post scrotal or post ischial depending upon calculi lodgement. However, postoperative complications associated with poor long term outcomes due to stricture formation, resulting in recurrent obstruction [26]. Bladder marsupialisation is 
another surgical option but the quality and duration of postoperative life may be limited by such problems as urine scald, urinary tract infection, stricture, and prolapse of bladder mucosa [27].

In ruptured urinary bladder most of the animals were treated with frusemide $\mathrm{HCl}$ by local veterinarians before presented to the hospital. Frusemide is a loop diuretic which increases the urine production by its loop diuretic action. Diuretics are recommended only for partial obstruction not for complete obstruction [1]. In complete obstruction, the production of urine was more because of diuretic action and it might have lead to cause rupture of the bladder. This could be one of the major factors for rupture of bladder in ruminants in our cases. When the urinary bladder ruptured, this gives relief for 1or 2 days. Thereafter animal may develop severe uremia and uroperitonium, which progress into severe depression, anorexia and severe dehydration. Cystorrhaphy followed by tube cystostomy was done for those ruptured cases.

The post operative complications recorded in few cases of our study, which includes urethral rupture and tube blockage. This may be due to medical mismanagement like not flushing the tube frequently; dislodgement of tube may be deflation of bulb of the catheter and dietary mismanagement.

\section{Conclusion}

In summary, our findings indicated that tube cystostomy is a quick, practicable, field applicable, and reliable method for the management of obstructive urolithiasis in ruminants. Surgical management along with medical management provided better treatment options for obstructive urolithiasis and prophylactic measures may be advised to owners.

\section{Authors' contributions}

PT, AM, MBG and Rashmi- Performed surgery in clinical cases. PT and KK prepared the manuscript. MG and MMSZ corrected the manuscript. All authors read and approved the final manuscript.

\section{Acknowledgements}

The Authors are thankful to director, Indian veterinary research institute for providing all the facilities and funds to carry out the present study.

\section{Competing interests}

The authors declare that they have no competing interests.

\section{References}

1. Radostitis, O.M., Blood, D.C., Gay, C.C., Hinchcliff, K.W. (2000) Veterinary Medicine: A Textbook of the Diseases of Cattle, Sheep, Pigs, Goats and Horses. Bailliere Tindall, London. p493-498.

2. Kushwaha, R.B., Gupta, A.K., Dwivedi, D.K. and Sharma, A. (2011) Obstructive urolithiasis in Small Ruminants and its surgical management. Intas Polivet, 12: 359-62.

3. Smith, M.C. and Sherman, D.M. (1994) Urinary System. In: Cann CG ed, Goat Medicine. Philadelphia: Lea \& Febiger, 398-402.p398-402.

4. Pond, W.G., Church, D.C., Pond, K.R. and Schoknecht, P.A.
(2005) Sheep and Goats. In: Raphael C, Wolfman,Robichaud S eds, Basic Animal Nutrition and Feeding. Hoboken: John Wiley and Sons, Inc. p 439-461.

5. Ewoldt, J.M., Jones, M.L. and Miesner, M.D. (2008) Surgery of obstructive urolithiasis in ruminants. Vet Clin North Am FoodAnim Pract, 24:455-65.

6. Fazili, M.R., Bhattacharyya, H.K., Buchoo, B.A. Malik, H.U. and Dar, S.H. (2012) Management of obstructive urolithiasis in dairy calves with intact bladder and urethra by Fazili's minimally invasive tube cystotomy technique, Vet. Sci.Dev., 2: 50-53.

7. Gasthuys, F., Steenhaut, M., De Moor, A. and Sercu, K. (1993) Surgical treatment of urethral obstruction due to grazed in pastures containing large quantities of urolithiasis in male cattle: a review of 85 cases. Vet. Rec. 133: 522-526.

8. Sharma, A.K., Mogha, I.V., Singh, G.R., Amarpal and Aithal, H.P. (2007) Incidence of urethral obstruction in animals. Indian J. Anim. Sci. 77: 455-56.

9. Kushwaha, R.B., Amarpal, Aithal, H.P., Kinjavdekar, P. and Pawde, A.M. (2014) Clinical Appraisal of 48 Cases of Obstructive Urolithiasis in Buffalo Calves Treated with Tube Cystostomy and Urethrotomy, Adv. Anim. Vet. Sci. 2 (2): 106 -110 .

10. Gugjoo, M.B., Zama, M.M.S., Amarpal, Mohsina, A, Saxena, A.C. and Sarode, I.P. (2013) Obstructive urolithiasis in buffalo calves and goats: incidence and management. $J$. Adv. Vet. Res. 3: 109-113.

11. Thilagar, S., Balasubramanian, N.N. and Archibald, D. (1996) A retrospective study of urinary obstruction in dogs-a radiographic study. Indian Vet. J. 73; 1183- 84.

12. Belknap, E.B. and Pugh, D.G. (2002) Diseases of the urinary system. Sheep and Goat Medicine. (Ed.) Pugh, D.G., W.B. Saunders Co. p 255-276.

13. Jones, M.L. and Miesner, M.D. (2009) Urolithiasis. In: Merchant $\mathrm{T}$ ed, Food Animal Practice $5^{\text {th }}$ ed. St Louis: Saunders. p322-325.

14. Unmack, A. (2011) Constituents of calculi from the urinary tract of bulls and bullocks. Evidence of silica urolithiasis in cattle in Denmark. Kongelige Veterinaer- og Landboho iskol- es Aarsskrift, 1963:1-12.

15. Singh, T. (2005) Studies on aetiopathogenesis and surgical management of urolithiasis in goats. PhD thesis, submitted to Deemed University, IVRI, India.

16. Lavania, JP, Misra, SS and Angelo, SJ. (1973). Repair of rupture of bladder in a calf-a clinical case. Indian Vet. J. 50: 477-481.

17. Kelly, W.R. (1984) The abdominal and associated digestive organs. In: Vet. clini diagnosis. Bailliere Tindall, London, 147-213.

18. Wilson, W.D. and Lofstedt, J. (1990) Alterations in respiratory functions. In: Large Animal Internal Medicine, C. V. S. Mosby Company, Philadelphia, p47-99.

19. Jadon, N.S., Prakash, P., Joshi, H.C. and Kumar, A. (1987) Clinico-haematological changes in experimental urethral obstruction in buffalo calves. Indian J. Vet. Med. 7: 49-51.

20. Parrah, J.D., Moulvi, B.A., Hussain, S.S., Bilal, S. and Ridwana (2011) Innovative tube cystostomy for the management of bovine clinical cases of obstructive urolithiasis. Vet. Arhiv 81 (3), 321-337.

21. Sockett, D.C., Knight, A.P., Fettman, M.J., Kiehl, A.R., Smith, J.A. and Arnold, S.M. (1986) Metabolic changes due to experimentally induced rupture of the bovine urinary bladder. Cornell Vet. 76:198-212.

22. Donecker, J.M. and Bellamy, J.E.C. (1982) Blood Chemical Abnormalities in Cattle with ruptured Bladders and Ruptured Urethras. Can. Vet. J. 23:355-357.

23. Ewoldt, J.M., Anderson, D.E., Miesner, M.D. and Saville,W.J. (2006) Short- and Long -Term Outcome and Factors Predicting Survival After Surgical Tube Cystotomy for Treatment of Obstructive Urolithiasis in Small Ruminants. Vet. Surg., 35:417-422.

24. Fortier, L.A., Gregg, A.J., Erb, H.N. and Fubini, S. C. (2004) 
Caprine obstructiveurolithiasis: Requirement for $2^{\text {nd }}$ surgical intervention and mortality after percutaneous 22 tube cystostomy, surgical tube cystostomy, or urinary bladder marsupialization. Vet Surg. 33: 661-667.

25. Parrah, J.D., Moulvi, B.A., Hussain, S.S., Bilal, S. and Ridwana (2010) Comparative efficacy of tube cystostomy and cystostomy with indwelling urethral catheterization in the management of obstructive urolithiasis in bovines.
Indian J. Vet. Surg. 31(2): 81-85.

26. Türk, T., Knoll, A., Petrik, K., Sarica, M. and Straub, C. (2012) Guidelines on Urolithiasis. J. Endourol., 15 (7): 671673.

27. May, K.A., Moll, H.D., Wallace, L.M., Pleasant, R.S. and Howard, R.D. (1998) Urinary Bladder Marsupialization for Treatment of Obstructive Urolithiasis in Male Goats. Vet. Surg., 27: 583-588.

$* * * * * * * *$ 